\title{
INTERAÇÃO SILÍCIO E ALUMÍNIO EM PLANTAS DE ARROZ DE TERRAS ALTAS CULTIVADAS EM SOLO ALUMÍNICO(1)
}

\author{
Lucas Barbosa de Freitas( ${ }^{(2)}$, Dirceu Maximino Fernandes ${ }^{(3)}$ \& Suelen \\ Cristina Mendonça Maia( ${ }^{(2)}$
}

\begin{abstract}
RESUMO
Solos com altos teores de $\mathrm{Al}$ tóxico podem causar diversos danos às plantas e, como consequência, diminuir sua produtividade; assim, seu manejo torna-se imprescindível para obter maiores produtividades, e o Si pode ser alternativa para diminuir a toxidez por $\mathrm{Al}$ em plantas. O objetivo deste trabalho foi avaliar a interação entre $\mathrm{Si}$ e $\mathrm{Al}$ em plantas de arroz de terras altas cultivadas em solo naturalmente alumínico de textura média arenosa. O delineamento experimental utilizado foi o de blocos inteiramente casualizados, dispostos em esquema fatorial $2 \times 5$ com quatro repetições. Os tratamentos empregados foram dois cultivares de arroz de terras altas: BRS Talento (não tolerante ao Al, moderno) e Guarani (tolerante ao $\mathrm{Al}^{3+}$, tradicional), além de cinco doses de $\mathrm{Si}\left(0,30,60,90 \mathrm{e} 120 \mathrm{mg} \mathrm{dm}^{-3}\right.$ ) adicionadas ao solo. $\mathrm{O} \mathrm{Si}$ fornecido ao solo contribuiu amenizando a toxidez por $\mathrm{Al}$ em ambos os cultivares, porém só houve acréscimo em produtividade no cultivar BRS Talento. Houve correlação positiva para produtividade de grãos do cultivar BRS Talento e teor de Si nas folhas; já o teor de $\mathrm{Al}$ nas folhas correlacionou-se com a produtividade de forma negativa; e também houve correlação negativa entre os teores de Si e $\mathrm{Al}$ nas folhas, indicando que há interação entre $\mathrm{Si}$ e $\mathrm{Al}$ em plantas de arroz.
\end{abstract}

Termos de indexação: Oriza sativa L., toxidez ao alumínio, silicato.

(1) Parte da Dissertação de Mestrado do primeiro autor apresentada ao programa de Pós-Graduação em Agricultura da Faculdade de Ciências Agronômicas, Universidade Estadual Paulista - FCA/UNESP. Recebido para publicação em 15 de agosto de 2011 e aprovado em 24 de janeiro de 2012.

(2) Doutorando em Agronomia (Agricultura), Faculdade de Ciências Agronômicas, Universidade Estadual Paulista -FCA/UNESP. Campus de Botucatu, Caixa Postal 237, CEP 18603-970 Botucatu (SP). E-mails: lucasbf@fca.unesp.br; suelen.maia@fca.unesp.br

(3) Professor Assistente Doutor do Departamento de Recursos Naturais - Ciência do Solo, FCA/UNESP. Bolsista do CNPq. E-mail: dmfernandes@fca.unesp.br 


\title{
SUMMARY: SILICON - ALUMINUM INTERACTION IN RICE CULTIVARS IN ALUMINOUS SOIL
}

\begin{abstract}
Soils with high levels of toxic Al can cause damage to plants and consequently decrease yields; a proper management is therefore essential to increase yields. Silicon can be a good alternative to reduce the toxicity of Al in the soil. The objective of this study was to evaluate the influence of the interaction between silicon and $\mathrm{Al}$ in rice plants grown in naturally aluminous soil. The experiment was arranged in a completely randomized, $2 \times 5$ factorial design with four replications. The treatments consisted of two highland rice cultivars: BRS Talento - susceptible to Al toxicity, modern; Guarani - tolerant to Al toxicity, traditional, and five Si rates $\left(0,30,60,90\right.$, and $\left.120 \mathrm{mg} \mathrm{dm}^{-3}\right)$. The Si supplied in soil contributes to decrease the Al toxicity in both cultivars. However the response in yield was noted only in BRS Talento cultivar. There was a positive correlation between yield of BRS Talento cultivar and Si content in leaves; Al content in leaves correlated negatively to yield; and the same behavior was noted between $\mathrm{Si}$ and $\mathrm{Al}$ in leaves. It can concluded that there is an interaction between $\mathrm{Si}$ and $\mathrm{Al}$ in plants of rice.
\end{abstract}

Index terms: Oriza sativa L., aluminium toxicity, silicate.

\section{INTRODUÇÃO}

A toxidez ao $\mathrm{Al}$ é um dos principais limitantes da produtividade em solos ácidos, os quais representam grande área com capacidade produtiva em regiões tropicais e subtropicais. Solos ácidos estão presentes em cerca de $40 \%$ da superfície terrestre (Kochian, 1995) e $70 \%$ dos solos potencialmente cultiváveis do mundo (Piñeros et al., 2002). No Brasil, a ocorrência de solos com problemas de toxidez de $\mathrm{Al}$ é da ordem de $60 \%$, considerando-se as terras com potencial para atividades agrícolas. Em geral, o $\mathrm{pH}$ da maioria dos solos brasileiros varia entre 3,7 e 5,5 , e o $\mathrm{Al}$ é o cátion predominante em mais de um terço dos solos com pH inferior a 5,6 (Abreu Jr. et al., 2003).

$\mathrm{O}$ primeiro sintoma de toxidez causado por $\mathrm{Al}$ nas plantas - que acontece inclusive em variedades tidas como tolerantes, porém em menor grau - é a inibição do crescimento e desenvolvimento das raízes, a qual ocorre cerca de uma a duas horas após a exposição ao $\mathrm{Al}^{3+}$ (Kochian, 1995), e isso, por conseguinte, influencia negativamente também a absorção radicular de água e nutrientes (Mistro et al., 2001; Wang et al., 2006). As raízes tornam-se atrofiadas em função da morte ou injúria do meristema radicular e aumenta a rigidez da parede celular (Schlindwein et al., 2003; Guimarães et al., 2006). Especificamente, a parte distal da zona de transição no ápice das raízes, onde as células estão entrando em fase de alongamento, é o sítio da ação tóxica primária do $\mathrm{Al}$ (Wang et al., 2006; Hartwig, et al., 2007). Dessa forma, as plantas afetadas apresentam redução do crescimento e, consequentemente, da produtividade.

$\mathrm{O}$ arroz de terras altas apresenta características de rusticidade, como tolerância a baixo $\mathrm{pH}$, baixo $\mathrm{V} \%$ e ao $\mathrm{Al}$, principalmente os cultivares considerados tradicionais (Fornasieri Filho \& Fornasieri, 2006). O baixo $\mathrm{pH}$ e V \% e a presença de Al trocável no solo limitam o crescimento das raízes nos primeiros centímetros do solo (Kochian, 1995), na maioria das vezes a menos de $10 \mathrm{~cm}$, onde se concentra a matéria orgânica. Em consequência, ocorre redução do volume de solo explorado pelas raízes, impossibilitando que as plantas desenvolvam todo seu potencial produtivo, principalmente pelo pequeno crescimento radicular, que impede que a planta busque água em camadas mais profundas do solo; assim, elas tornam-se mais suscetíveis ao estresse hídrico, limitando a absorção de nutrientes e o potencial produtivo do cultivar (Jansen et al., 2002; Chaffai et al., 2005).

Por outro lado, plantas de arroz de terras altas absorvem e acumulam elevada quantidade de Si, elemento este que é considerado benéfico (Epstein, 1999; Korndörfer, 2006). Nas plantas, seu efeito mais evidente é observado em cultivos sob condições de estresse (Ma, 2004). Isso ocorre porque o Si é capaz de proteger as plantas contra vários estresses bióticos e abióticos (Lux et al., 2002; Ma \& Yamaji, 2006), entre eles o estresse por Al. Contudo, a interação entre $\mathrm{Si}\left(\mathrm{H}_{4} \mathrm{SiO}_{4}\right)$ e $\mathrm{Al}$ ainda é pouco conhecida: há diversas hipóteses para a amenização do $\mathrm{Al}$ pelo $\mathrm{Si}$, mas nenhuma conclusiva (Ma et al., 1997).

Algumas hipóteses aceitas (Cocker et al., 1998) são baseadas em mecanismos internos das plantas. As acumulações de $\mathrm{Al}$ e Si na parte aérea das plantas são mutuamente exclusivas, isto é, quando o Si é absorvido pela planta na forma de ácido monossilício $\left(\mathrm{H}_{4} \mathrm{SiO}_{4}\right)$, o $\mathrm{Al}$ deixa de sê-lo. A tolerância de algumas espécies ao $\mathrm{Al}$, entre outros fatores, pode estar associada à maior absorção e acumulação de Si nos tecidos da planta.

O objetivo deste trabalho foi avaliar a interação entre $\mathrm{Si}$ e $\mathrm{Al}$ tóxico em plantas de arroz de terras altas cultivadas em solo naturalmente alumínico de textura média arenosa. 


\section{MATERIAL E MÉTODOS}

O experimento foi conduzido em túnel plástico, pertencente ao Departamento de Recursos Naturais - Ciência do Solo da Faculdade de Ciências Agronômicas, Universidade Estadual Paulista UNESP - campus de Botucatu, localizada a $48^{\circ} 23^{\prime} \mathrm{W}$ e $22^{\circ} 51^{\prime} \mathrm{S}$, a $765 \mathrm{~m}$ de altitude.

O solo utilizado no experimento foi de baixa fertilidade natural e alumínico, classificado como Latossolo Vermelho-Escuro textura média arenosa, que apresentava as seguintes características químicas: $7 \mathrm{mg} \mathrm{dm}^{-3}$ de P-resina; $15 \mathrm{~g} \mathrm{dm}^{-3}$ de $\mathrm{MO} ; 4,1 \mathrm{pH}$ em $\mathrm{CaCl}_{2} ; 0,7,5,3,69,11$ e $78 \mathrm{mmol}_{\mathrm{c}} \mathrm{dm}^{-3} \mathrm{de} \mathrm{K}, \mathrm{Ca}$, $\mathrm{Mg}, \mathrm{H}+\mathrm{Al}, \mathrm{Al}^{3+}$ e CTC, respectivamente; $2 \mathrm{mg} \mathrm{kg}^{-1}$ de Si (Cloreto de cálcio 0,01 M).

Adotou-se o delineamento experimental em blocos casualizados, em esquema fatorial $2 \times 5$, com quatro repetições. Os tratamentos foram dois cultivares de arroz de terras altas: BRS Talento - não tolerante (Silva, 2007) e Guarani - tolerante ao $\mathrm{Al}$ (Ferreira et al., 1995), além de cinco doses de $\mathrm{Si}(0$, 30, 60, 90 e $120 \mathrm{mg} \mathrm{dm}^{-3}$ ). A fonte de Si utilizada foi o silicato de potássio, o qual apresentou as seguintes garantias: $25 \%$ de $\mathrm{SiO}_{2}$ e $15 \%$ de $\mathrm{K}_{2} \mathrm{O}$. O $\mathrm{K}$ foi balanceado em todas as parcelas em que foi aplicado o silicato de potássio, com a adição de $\mathrm{KCl}$, até atingir o nível de $\mathrm{K}$ recomendado por Novais et al. (1991). A adubação silicatada foi realizada logo após a semeadura, solubilizando o silicato de potássio em água e aplicando sobre a superfície do solo.

No dia anterior à semeadura o solo foi peneirado e, em seguida, colocado em vasos. Foram utilizados como parcela experimental vasos com capacidade para $40 \mathrm{~L}$ de solo $(0,4 \times 0,3 \times 0,4 \mathrm{~m})$, tendo $0,12 \mathrm{~m}^{2}$ como área útil. A semeadura dos dois cultivares foi feita no dia 8 de janeiro de 2010, utilizando-se 100 sementes em uma linha de $0,40 \mathrm{~m}$ por vaso. Antes da semeadura as sementes foram tratadas com o fungicida carboxin + tiram $(60+60 \mathrm{~g}$ do i.a. por $100 \mathrm{~kg}$ de sementes) e o inseticida tiametoxam (140 g do i.a. por $100 \mathrm{~kg}$ de semente).

A emergência dos cultivares foi verificada em seis e oito dias após a semeadura (DAS) para os cultivares Guarani e BRS Talento, respectivamente. Após a emergência das plantas, foi realizado desbaste, de modo que cada unidade experimental apresentasse 30 plantas.

A adubação na semeadura foi realizada de acordo com as recomendações de Novais et al. (1991) para experimentação em vasos com solo. Como fonte de $\mathrm{N}, \mathrm{P}, \mathrm{K}$ e Mg utilizou-se ureia, superfosfato triplo, cloreto de potássio e cloreto de magnésio, respectivamente. A adubação nitrogenada foi parcelada em três vezes, sendo a primeira aplicada na semeadura, a segunda, aos 32 DAS, e a terceira, aos 55 DAS.
Os tratamentos fitossanitários para controle de brusone realizados durante a condução do experimento foram: uma aplicação de trifloxistrobina + propiconazol, na dose de $93,75+93,75$ i.a. ha ${ }^{-1}$; uma aplicação de difenoconazol, na dose de 0,3 i.a. ha ${ }^{-1}$; e uma aplicação de mancozebe, na dose de 4,5 i.a. ha ${ }^{-1}$.

O florescimento dos cultivares ocorreu aos $83 \mathrm{e}$ 101 DAS para o Guarani e BRS Talento, respectivamente. A coleta da folha-bandeira para diagnose foliar de $\mathrm{Al}$ e Si foi realizada aos 89 e 110 DAS para os cultivares Guarani e BRS Talento, respectivamente. Para diagnose foliar, foram coletadas 50 folhas-bandeira em cada unidade experimental.

A colheita do cultivar Guarani foi realizada aos 111 DAS, e a do cultivar BRS Talento, aos 138 DAS. As panículas foram deixadas a pleno sol para secar; após secas, foram trilhadas, com a finalidade de separar os grãos da palha.

Foram realizadas as seguintes avaliações: altura da planta, número de perfilhos por planta, produção de matéria seca, número de colmos por metro quadrado, percentagem de colmos férteis, número de panículas, número total de espiguetas por panícula, número de espiguetas granadas e chochas por panícula, fertilidade das espiguetas, massa de mil grãos, produtividade de grãos, correlações entre os teores de $\mathrm{Si}$ e $\mathrm{Al}$ na folha-bandeira e produtividade de grãos.

Os resultados do experimento foram submetidos à análise de variância pelo teste $\mathrm{F}$. Os cultivares foram comparados pelo teste t (DMS) a $5 \%$, enquanto os efeitos das doses de Si foram avaliados por meio de análise de regressão. Os modelos foram escolhidos com base na significância dos coeficientes de regressão, utilizando-se o teste t a $5 \%$, e no coeficiente de determinação.

Foram estabelecidas correlações lineares como medida de dependência entre os teores de $\mathrm{Si}$ e $\mathrm{Al}$ e produtividade de grãos. A fim de verificar a significância do coeficiente de correlação, utilizou-se $o$ teste $t$.

\section{RESULTADOS E DISCUSSÃO}

A aplicação de Si não influenciou a altura de plantas dos cultivares (Quadro 1). O Si tem a propriedade de alterar a arquitetura das plantas, deixando-as mais eretas (Epstein, 1999), o que não contribui para acréscimo na altura de plantas; além disso, altura de plantas é característica genética de alta herdabilidade.

Ao comparar os dois cultivares, pode-se reforçar a tese de que a altura é uma característica genética ligada à planta, devido à diferença encontrada entre 
Quadro 1. Altura de planta, número de colmos por metro quadrado, número de perfilho por planta e número de panículas por metro quadrado, em função da aplicação de Si nos cultivares de arroz

\begin{tabular}{lcccc}
\hline Cultivar & Altura da planta & Número de colmos & Número de panículas & Número de perfilho/planta \\
\hline & $\mathrm{cm}$ & $844,5 \mathrm{~b}$ & $\mathrm{n}^{\circ} \mathrm{m}^{-2}$ & $\mathrm{n}^{\circ}$ \\
Guarani & $117,5 \mathrm{a}$ & $1005,4 \mathrm{a}$ & $833,7 \mathrm{a}$ & $3,3 \mathrm{~b}$ \\
BRS Talento & $90,6 \mathrm{~b}$ & 7,1 & $882,5 \mathrm{~b}$ & $4,0 \mathrm{a}$ \\
CV (\%) & 6,3 & 8,0 & 7,1 \\
\hline
\end{tabular}

Médias seguidas de letras diferentes, dentro de cada característica avaliada, diferem entre si pelo teste t a $5 \%$.

os cultivares: o cultivar Guarani apresentou altura superior em comparação ao BRS Talento (Quadro 1). Ainda, segundo Breseghello et al. (1998), cultivares do grupo tradicional, como o Guarani, apresentam plantas com altura elevada, raízes profundas, baixo perfilhamento e tolerância a solos com baixos níveis de fertilidade.

O número de colmos por metro quadrado e o número de perfilho por planta não foram influenciados pela aplicação de Si (Quadro 1). Sabe-se que o Si tem efeito benéfico, influenciando de diversas formas as plantas, principalmente quanto a estresse bióticos e abióticos (Ma \& Yamaji, 2006), porém não é relatado efeito sobre o número de colmos por metro quadrado e perfilhos por planta (Mauad et al., 2003; Alvarez, 2004). Esses resultados estão de acordo com Fageria (1984), o qual afirma que os nutrientes necessários para um ativo perfilhamento são $\mathrm{N}, \mathrm{P}$ e S. A não resposta positiva à aplicação de Si está de acordo com os resultados obtidos por Assis et al. (2000) e Benedito (2004), que não evidenciaram aumento significativo nos componentes de crescimento para cultivares de arroz.

No entanto, houve diferença para números de colmos por metro quadrado entre os cultivares. $\mathrm{O}$ cultivar BRS Talento apresentou maior perfilhamento por planta e, consequentemente, maior número de colmos por metro quadrado (Quadro 1). Ele apresentou maior número de colmos por metro quadrado em relação ao Guarani (Quadro 1). Esse resultado está relacionado à característica genética dos cultivares: cultivares do grupo moderno, como o BRS Talento, foram melhorados geneticamente, em busca de características para maior capacidade de perfilhamento, objetivando alta produtividade (Breseghello et al., 1998).

O número de colmos por metro quadrado não é um componente da produção, porém indica a capacidade de perfilhamento do cultivar, sendo influenciado principalmente pela genética do cultivar (Breseghello et al., 1998). Um cultivar perfilha mais, outro menos, porém, dependendo das condições, um cultivar pode perfilhar muito, mas pode não transformar esse alto perfilhamento em alta produtividade.

Os tratamentos com Si não influenciaram o número de panículas por metro quadrado (Quadro 1) e a percentagem de colmos férteis (Figura 1a). Entretanto, houve diferença entre os cultivares, com o BRS Talento mostrando maior número de panículas por metro quadrado (Quadro 1). Apesar de este cultivar apresentar maior número de panículas, devido a seu alto perfilhamento, apresentou menor percentagem de colmos férteis (Quadro 2).

O cultivar Guarani mostrou maior percentagem de colmos férteis (Quadro 2), por ser considerado rústico, "tradicional" e tolerante ao $\mathrm{Al}$; dessa forma, apresentou-se mais adaptado às condições do experimento, onde o solo apresentava-se principalmente com baixo $\mathrm{pH}$ e $\mathrm{V} \%$ e altos teores de Al trocável (Terres et al., 2004; Fornasieri Filho \& Fornasieri 2006).

Por outro lado, o cultivar BRS Talento - não tolerante ao $\mathrm{Al}$, melhorado geneticamente e com maior potencial produtivo - apresentou menor percentagem de colmos férteis em razão de sua maior exigência em fertilidade do solo; mesmo com a suplementação de nutrientes via adubação, o solo não se encontrava em condições ideais para o cultivar alcançar o máximo de seu potencial produtivo. Embora tenha perfilhado bastante, como as condições de fertilidade do solo não foram totalmente favoráveis, o cultivar produziu menor número de panículas.

A percentagem de colmos férteis mostra a quantidade de colmos que passaram da fase vegetativa para a reprodutiva. Em outras palavras, essa variável demonstra o valor do número de colmos que possuíam panículas no momento da colheita, fazendo com que influencie diretamente a produtividade de grãos. A passagem de fase vegetativa para reprodutiva, além de ser sensível a condições climáticas, requer também teores adequados de nutrientes, e cada cultivar tem sua característica. O cultivar BRS Talento, por ser melhorado geneticamente, apresenta maior capacidade produtiva e necessita de solos com fertilidade superior, ao contrário do 
Quadro 2. Percentagem de colmos férteis, número de espiguetas por panícula, número de espiguetas granadas por panícula e número de espiguetas chochas por panículas, em função da aplicação de $\mathrm{Si}$ nos cultivares de arroz

\begin{tabular}{lcccc}
\hline Cultivar & $\begin{array}{c}\text { Percentagem de } \\
\text { colmos férteis }\end{array}$ & $\begin{array}{c}\text { Espiguetas/ } \\
\text { panículas }\end{array}$ & $\begin{array}{c}\text { Espiguetas granadas/ } \\
\text { panícula }\end{array}$ & $\begin{array}{c}\text { Espiguetas chochas/ } \\
\text { panícula }\end{array}$ \\
\hline & $\%$ & & $\mathrm{n}^{\circ}$ & $7,6 \mathrm{~b}$ \\
Guarani & 98,7 & 106,1 & $98,4 \mathrm{a}$ & $57,1 \mathrm{a}$ \\
BRS Talento & 97,7 & 114,9 & $57,8 \mathrm{~b}$ & 44,3 \\
CV (\%) & 5,1 & 13,0 & 21,9 & \\
\hline
\end{tabular}

Médias seguidas de letras diferentes, dentro de cada característica avaliada, diferem entre si pelo teste t a $5 \%$.

cultivar Guarani, adaptado a solos com baixo teor de nutrientes e altos níveis de $\mathrm{Al}^{3+}$, como o solo utilizado no experimento.

Não houve diferença no número de espiguetas por panículas com a aplicação de Si (Figura 1b), bem como não houve diferença para essa característica entre os cultivares (Quadro 2). Por sua vez, o número de espiguetas granadas e chochas por panícula foi influenciado pela aplicação de Si (Figura 1c,d).

A aplicação de Si influenciou somente o cultivar BRS Talento para espiguetas granadas e chochas por panícula. Pelo fato de o cultivar ser mais exigente nutricionalmente para expressar seu maior potencial produtivo e as condições do solo onde foi realizado o experimento não serem ideais quanto à fertilidade do solo, sobretudo devido ao $\mathrm{pH}$ e $\mathrm{V} \%$ baixos, o cultivar BRS Talento obteve baixa produtividade. Assim, com a aplicação de Si, observou-se aumento no número de espiguetas granadas e diminuição no número de espiguetas chochas. O aumento de grãos granados com a aplicação de Si pode estar relacionado ao melhor aproveitamento da água pelo cultivar BRS Talento, proporcionado pelo Si (Gao et al., 2004).

Esses resultados estão de acordo com os obtidos por Houssain et al. (2001), que constataram que o número de espiguetas chochas foi reduzido com o fornecimento de Si para as plantas de arroz.

Ao comparar os cultivares, os números de espiguetas granadas e chochas por panícula foram diferentes (Quadro 2): o cultivar Guarani mostrou maior número de grãos granados em comparação ao BRS Talento, enquanto este apresentou maior número de grãos chochos. Isso reforça a hipótese de que o cultivar BRS Talento é mais exigente em fertilidade do solo, como discutido anteriormente;
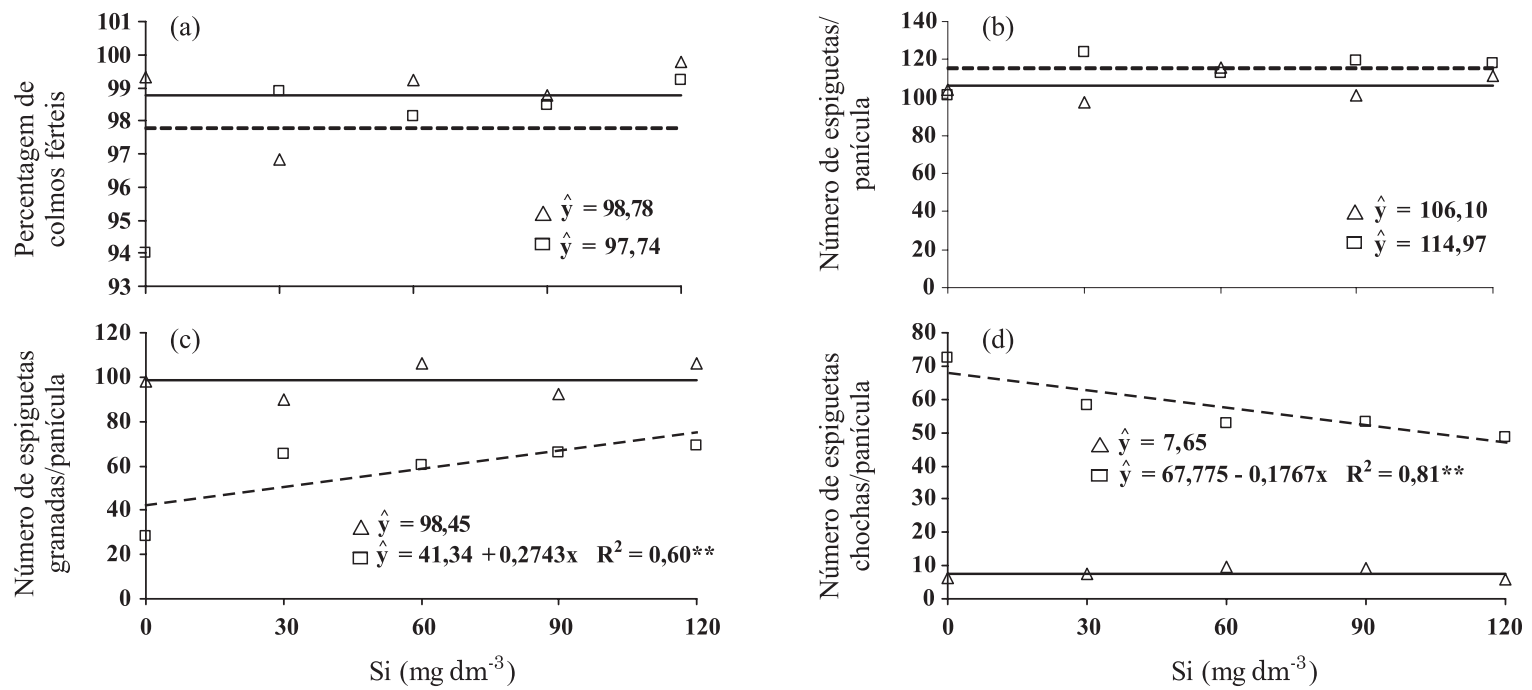

Figura 1. Percentagem de colmos férteis (a), número de espiguetas por panícula (b), número de espiguetas granadas por panícula (c) e número de espiguetas chochas por panícula (d) dos cultivares de arroz Guarani $(\Delta)$ e BRS Talento ( $\square$ ), em função de doses de silício. * e ** são, respectivamente, significativos a $5 \%$ e $1 \%$ pelo teste $t$. 
as condições do solo do experimento influenciaram negativamente o número de grãos granados e o alto número de grãos chochos obtidos por este cultivar.

Outra possibilidade para explicar a diferença entre os cultivares quanto ao número de grãos chochos e granados pode ser o alto perfilhamento do cultivar BRS Talento (Quadro 1). Pelo fato de o solo não apresentar condições de fertilidade adequadas, a planta não consegue granar todos os grãos, por isso, o alto número de grãos chochos no cultivar BRS Talento. Já o cultivar Guarani, considerado "rústico" e tolerante ao $\mathrm{Al}$, tem melhor desempenho quando cultivado em solos com baixa fertilidade e alto teor de $\mathrm{Al}$, como o do experimento. Isso explica o fato de o cultivar Guarani apresentar maior número de grãos granados e baixo número de grãos chochos.

Assim como ocorreu para o número de grãos granados e chochos, a fertilidade de espiguetas foi influenciada pela aplicação de Si apenas para o cultivar BRS Talento (Figura 2a). Como a fertilidade de espiguetas é a relação entre número de espiguetas granadas por panícula e número total de espiguetas por panícula, o comportamento é o mesmo observado nas variáveis número de espiguetas granadas e número de espiguetas chochas. A fertilidade de espiguetas começa a ser definida desde a diferenciação do primórdio da panícula até o emborrachamento (Fornasieri Filho \& Fornasieri, 2006).

Também houve diferença entre os cultivares quanto à fertilidade de espiguetas (Quadro 3). De forma semelhante ao ocorrido com os grãos granados, o cultivar Guarani também apresentou maior fertilidade de espiguetas, em razão de ser mais adaptado às condições de baixa fertilidade de solo. Já o cultivar BRS Talento, mesmo apresentando maior potencial produtivo, foi limitado pela fertilidade do solo e presença do Al. A diferença de fertilidade de espiguetas entre os cultivares foi de quase $50 \%$, fazendo com que essa variável influencie diretamente a produtividade de grãos dos cultivares.

A produção de matéria seca da parte aérea não foi alterada com a aplicação de Si (Figura $2 b$ ), porém houve diferença entre os cultivares. O cultivar BRS
Talento apresentou maior produção de matéria seca (Quadro 3), em razãao de seu maior perfilhamento (Quadro 1), produzindo maior quantidade de matéria seca. Esses resultados estão de acordo com o obtido por Mauad (2006), que, ao comparar o cultivar de arroz Caiapó do grupo tradicional e Maravilha do grupo moderno, constatou que este último obteve maior produção de matéria seca, bem como correlacionou-se com o maior número de colmos produzidos.

Mesmo o cultivar BRS Talento produzindo maior quantidade de matéria seca em comparação ao Guarani, sua produtividade de grãos foi inferior (Quadro 3). Isso ocorreu devido ao BRS Talento ter maior potencial produtivo; ao aumentar sua massa de matéria seca, na fase de enchimento de grãos, o solo não supriu suas exigências em fertilidade, gerando baixo número de grãos granados e alto número de grãos chochos, com reflexo na produtividade de grãos.

Houve diferença para massa de mil grãos com a aplicação de Si (Figura 2c) apenas para o cultivar Guarani. Gao et al. (2004) justificam essa ocorrência devido ao Si ter melhorado o aproveitamento de água pela planta durante a fase de enchimento de grãos. Contudo, esse efeito não se refletiu em produtividade de grãos (Figura 2d).

Ao comparar os cultivares, o Guarani obteve maior massa de mil grãos (Quadro 3). Isso era esperado, já que o cultivar Guarani apresenta grãos longos, enquanto o BRS Talento possui grãos longos e finos. Essa variável está altamente relacionada com a característica genética da planta, sendo esta característica varietal dependente do tamanho da casca, determinada duas semanas anteriores à antese, e do desenvolvimento da cariopse após o florescimento (Yoshida, 1981). É importante citar que o fato de o cultivar Guarani apresentar maior massa de mil grãos contribuiu, consequentemente, para sua maior produtividade de grãos (Quadro 3).

A aplicação de Si promoveu maior produtividade de grãos apenas para o cultivar BRS Talento (Figura 2d). Isso ocorreu em razão de o Si ter influenciado de forma crescente o número de grãos granados por

Quadro 3. Fertilidade de espiguetas, matéria seca da parte aérea, massa de mil grãos e produtividade de grãos, em função da aplicação de Si nos cultivares de arroz

\begin{tabular}{lcccc}
\hline Cultivar & $\begin{array}{c}\text { Fertilidade de } \\
\text { espiguetas }\end{array}$ & $\begin{array}{c}\text { Matéria seca da parte } \\
\text { aérea }\end{array}$ & Massa de mil grãos & $\begin{array}{c}\text { Produtividade de } \\
\text { grãos }\end{array}$ \\
\hline Guarani & $\%$ & $\mathrm{~g} \mathrm{~m}^{-2}$ & $\mathrm{~g}$ & $\mathrm{~g} \mathrm{~m}^{-2}$ \\
BRS Talento & $92,7 \mathrm{a}$ & $2068,1 \mathrm{~b}$ & $34,2 \mathrm{a}$ & $2009 \mathrm{a}$ \\
CV(\%) & $49,9 \mathrm{~b}$ & $2442,1 \mathrm{a}$ & $22,4 \mathrm{~b}$ & $1090 \mathrm{~b}$ \\
\hline
\end{tabular}

Médias seguidas de letras diferentes, dentro de cada parâmetro, diferem entre si pelo teste t a $5 \%$. 

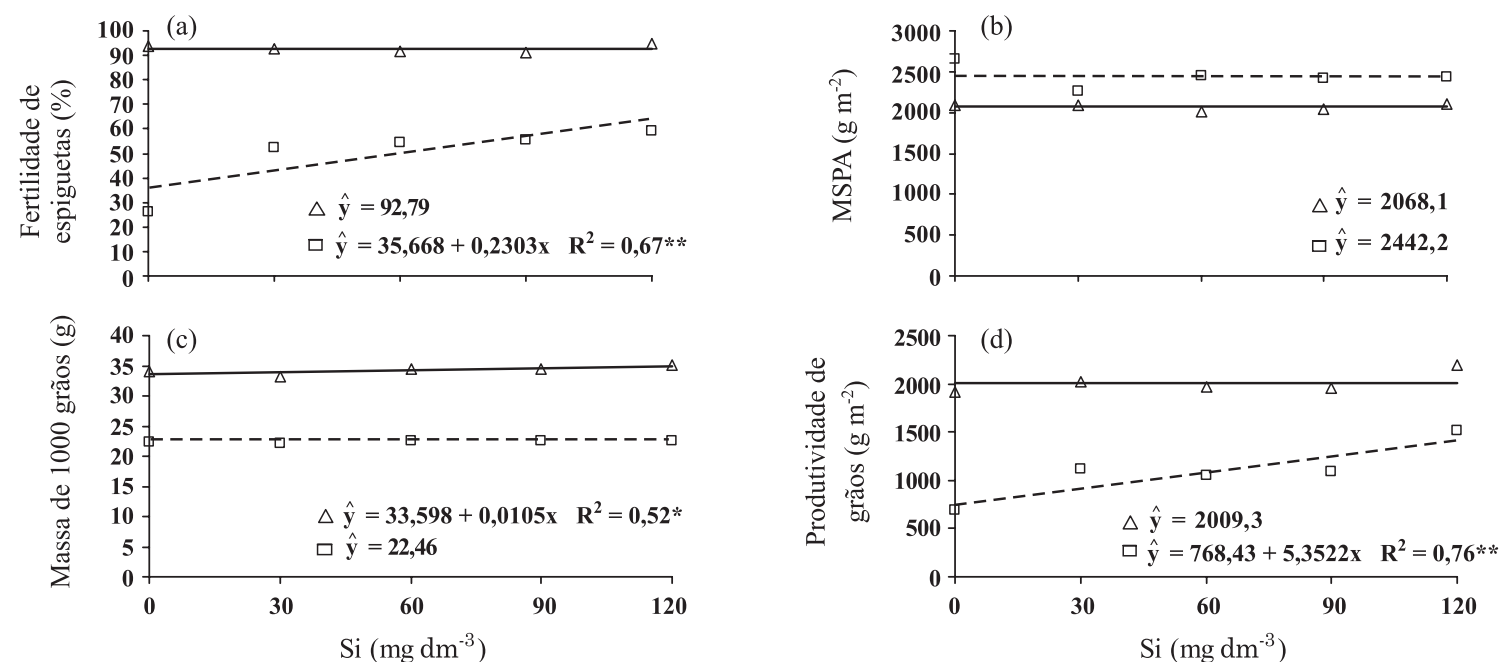

Figura 2. Fertilidade de espiguetas (a), matéria seca da parte aérea - MSPA (b), massa de mil grãos (c) e produtividade de grãos (d) dos cultivares de arroz Guarani ( $\Delta$ ) e BRS Talento ( $\square$ ), em função de doses de silício. * $\mathrm{e} *$ são, respectivamente, significativos a 5 e $1 \%$ pelo teste $\mathrm{t}$.

panícula (Figura 1c) e a fertilidade de espiguetas (Figura 2a) desse cultivar; dessa forma, a produtividade de grãos obteve o mesmo comportamento, por essas variáveis influenciarem-na diretamente. Esses resultados estão de acordo com os obtidos por Mauad (2006), que, ao aplicarem o Si, observaram aumento na produtividade de grãos de arroz.

O aumento em produtividade do cultivar BRS Talento pode estar relacionado ao fato de ele ser exigente em fertilidade de solo; como foi cultivado sob condições de baixa fertilidade de solo e com alto teor de Al trocável no solo, o Si foi capaz de amenizar o estresse para esse cultivar, que é mais exigente em nutrientes e sensível ao $\mathrm{Al}$, obtendo produtividade de grãos superior em comparação ao tratamento sem $\mathrm{Si}$. Contudo, a máxima dose de Si para o cultivar BRS Talento alcançou produtividade de $1.512 \mathrm{~g} \mathrm{~m}^{-2}$, ainda abaixo da menor produtividade obtida pelo cultivar Guarani: $1.913 \mathrm{~g} \mathrm{~m}^{-2}$. No entanto, vale ressaltar que a massa de mil grãos do cultivar Guarani é superior à do cultivar BRS Talento.

Os resultados obtidos foram semelhantes aos encontrados por Rahman et al. (1998), que, ao aplicarem doses de $\mathrm{Si}$ e $\mathrm{Al}$ em cultivares sensíveis e tolerantes ao Al, observaram maior amenização da toxidez ao $\mathrm{Al}$ nos cultivares sensíveis ao $\mathrm{Al}$.

Houve diferença entre os cultivares para a produtividade de grãos (Quadro 3). Isso aconteceu pelo fato de o cultivar Guarani apresentar maior massa de mil grãos e fertilidade de espiguetas, mas também, principalmente, por ele ser mais adaptado a condições de baixa fertilidade de solo, em comparação ao cultivar BRS Talento.

Esses resultados podem estar relacionados às características genéticas do cultivar Guarani, o qual pertence ao grupo Tradicional, cujos cultivares são "rústicos" e foram selecionados para solos com baixos níveis de fertilidade; além disso, apresentam tolerância à seca e maior estabilidade de produção de grãos (Terres et al., 2004; Fornasieri Filho \& Fornasieri 2006).

Não houve correlação entre produtividade de grãos e teores de $\mathrm{Si}$ e $\mathrm{Al}$ nas folhas das plantas do cultivar Guarani (Quadro 4), porém houve correlação negativa entre teores de $\mathrm{Si}$ e $\mathrm{Al}$ (Quadro 4). Assim, com a aplicação de Si, houve aumento no teor de Si e decréscimo de Al nas folhas, o que está em concordância com a hipótese proposta por Cocker et al. (1998), os quais afirmam que, quando o Si é absorvido pela planta, o $\mathrm{Al}$ deixa de sê-lo.

Para o cultivar BRS Talento houve correlação positiva entre a produtividade e o teor de Si nas folhas; já o teor de $\mathrm{Al}$ correlacionou-se com a produtividade de forma negativa, e também houve correlação negativa entre os teores de $\mathrm{Si}$ e $\mathrm{Al}$ (Quadro 4). Isso demonstra que, assim como para o cultivar Guarani, há aumento no teor de $\mathrm{Si}$ e decréscimo no teor de $\mathrm{Al}$ nas folhas. No entanto, para o cultivar BRS Talento há correlação com produtividade; assim, existe relação entre o aumento do teor de Si e decréscimo de Al nas folhas e o aumento de produtividade de grãos do cultivar.

Além da amenização da toxidez por Al, pode-se atribuir outro benefício ao Si no aumento da produtividade de grãos do cultivar BRS Talento (Figura 2d): a planta com maior teor de Si tem melhor aproveitamento da água (Gao et al., 2004). Dessa forma, há melhor aproveitamento de nutrientes e o enchimento de grãos é mais eficiente, influenciando o número de grãos granados e a fertilidade de espiguetas e, consequentemente, refletindo em produtividade de grãos. 
Quadro 4. Coeficientes de correlação linear simples entre produtividade de grãos e teores de Si e Al na folha bandeira, em função da aplicação de Si nos cultivares de arroz

\begin{tabular}{lcc}
\hline Variável & Teor de Al & Teor de Si \\
\hline \multicolumn{2}{c}{ Guarani } \\
Produtividade & ns & $\mathrm{ns}$ \\
Teor de Si & $-0.723^{* * *}$ & - \\
& \multicolumn{2}{c}{ BRSTalento } \\
Produtividade & $-0.591^{* *}$ & $0.596^{* *}$ \\
Teor de Si & $-0.734^{* * *}$ & -
\end{tabular}

*, $* *, * * *$ e ns são, respectivamente, significativos a $5,1,0,1 \% \mathrm{e}$ não significativo pelo teste $t$.

Vale ressaltar que antes do início do experimento o teor de $\mathrm{Al}$ trocável no solo era de $11 \mathrm{mmol}_{\mathrm{c}} \mathrm{dm}^{-3}$ e, após a colheita das plantas, de $10 \mathrm{mmol}_{\mathrm{c}} \mathrm{dm}^{-3}$. Quando calculada a saturação por $\mathrm{Al}^{3+}(\mathrm{m} \%)$, o valor inicial era de $55 \%$ e, após a colheita, de $47 \%$ - variação essa obtida em função das bases adicionadas via fertilizantes.

\section{CONCLUSÕES}

1. O Si fornecido ao solo contribui amenizando a toxidez por $\mathrm{Al}$ em ambos os cultivares, porém só há acréscimo em produtividade no cultivar BRS Talento.

2. Há correlação positiva para produtividade de grãos do cultivar BRS Talento e teor de Si nas folhas; já o teor de Al nas folhas correlaciona-se com a produtividade de forma negativa; e também há correlação negativa entre os teores de $\mathrm{Si}$ e $\mathrm{Al}$ nas folhas, indicando que há interação entre $\mathrm{Si}$ e $\mathrm{Al}$ em plantas de arroz.

\section{AGRADECIMENTOS}

À FAPESP, pela concessão de bolsa ao primeiro autor e pelo financiamento do projeto. Ao CNPq, pela concessão de bolsa ao segundo autor.

\section{LITERATURA CITADA}

ABREU JR, C.H.; MURAOKA, T. \& LAVORANTE, A. Relationship between acidity and chemical properties of Brazilians soils. Sci. Agric., 60:337-343, 2003.
ALVAREZ, A.C.C. Produção do arroz em função da adubação com silício e nitrogênio no sistema de sequeiro e irrigado por aspersão. Botucatu, Universidade Estadual Paulista, 2004. 70p. (Tese de Mestrado)

ASSIS, M.P.; CARVALHO, J.G.; CURI, N.; BERTONI, J.C. \& ANDRADE, W.E.B. Limitações nutricionais para a cultura do arroz em solos orgânicos sob inundação. I. Crescimento. Ci. Agrotec., 24:87-95, 2000.

BENEDITO, D.S. Interação boro x silício na nutrição, crescimento e produção do arroz. Lavras, Universidade Federal de Lavras, 2004. 62p. (Tese de Mestrado)

BRESEGHELLO, F.; CASTRO, E.M. \& MORAIS, O.P. Cultivares de arroz. In: BRESEGHELLO, F. \& STONE, L.F., eds. Tecnologia para arroz de terras altas. Santo Antonio de Goiás, Embrapa Arroz e Feijão, 1998. p.41-53.

COCKER, K.M.; EVANS, D.E. \& HODSON, M.J. The amelioration of aluminium toxicity by silicon in higher plants: Solution chemistry or an in planta mechanism. Plant Physiol., 104:608-614, 1998.

CHAFFAI, R.; MARZOUK, B. \& EL FERJANI, E. Aluminum mediates compositional alterations of polar lipid classes in maize seedlings. Phytochemistry, 66:1903-1912, 2005.

EPSTEIN, E. Silicon. Ann. Rev. Plant Physiol. Plant Molec. Biol., 50:641-664, 1999.

FAGERIA, N.K. Resposta de cultivares de arroz à aplicação de calcário em solo de cerrado. Pesq. Agropec. Bras., 19:883889, 1984.

FERREIRA, R.P.; CRUZ, C.D.; SEDIYAMA, C.S. \& FAGERIA N.K. Identificação de cultivares de arroz tolerantes à toxidez de alumínio por técnica multivariada. Pesq. Agropec. Bras., 30:789-795, 1995.

FORNASIERI FILHO, D. \& FORNASIERI, J.L. Manual da cultura do arroz. Jaboticabal, FUNEP, 2006. 589p.

GAO, X.; ZOU, C.; WANG, L. \& ZHANG, F. Silicon improves water use efficiency in maize plants. J. Plant Nutr., 27:1457. 1470,2004

GUIMARÃES, C.M.; NEVES, P.C.F.; STONE, L.F. \& ZIMMERMANN, F.J.P. Resistência do arroz de terras altas ao alumínio. R. Bras. Eng. Agríc. Amb., 10:855-860, 2006.

HARTWIG, I.; OLIVEIRA, A.C.; CARVALHO, F.I.F.; BERTAN, I.; SILVA, J.A.G.; SCHMIDT, D.A.M.; VALÉRIO, I.P.; MAIA, L.C.; FONSECA, D.A.R. \& REIS, C.E.S. Mecanismos associados à tolerância ao alumínio em plantas. Semina $\mathrm{Ci}$. Agr., 28:219-228, 2007.

HOSSAIN, K.A.; HORIUCHI, T. \& MIYAGAWA, S. Effects of silicate materials on growth and grain yield of rice plants grown in clay loam and sandy loam soils. J. Plant Nutr., 24:1-13, 2001.

JANSEN, S.; BROADLEY, M. \& ROBBRECHT, E. Aluminum hyperaccumulation in angiosperms: A review of its phylogenetic significance. Bot. Rev., 68:235-269, 2002.

KOCHIAN, L.V. Cellular mechanisms of aluminum toxicity and resistance in plants. Ann. Rev. Plant Physiol. Plant Molec. Biol., 46:237-260, 1995. 
KORNDÖRFER, G.H. Elementos benéficos. In: FERNANDES, M.S., ed. Nutrição mineral de plantas. Viçosa, MG, Sociedade Brasileira de Ciência do Solo, 2006. p.355-374.

LUX, A.; LUXOVÁ, M.; HATTORI, T.; INANAGA, S. \& SUGIMOTO, Y. Silicification in sorghum (Sorghum bicolor) cultivars with different drought tolerance. Plant Physiol., 115:87-92, 2002.

MA, J.F.; SASAKI, M. \& MATSUMOTO, H. Al-induced inhibition of root elongation in corn, Zea mays L. is overcome by $\mathrm{Si}$ addition. Plant Soil, 188:171-176, 1997.

MA, J.F. Role of silicon in enhancing the resistanc of plants to biotic and abiotic stresses. Soil Sci. Plant Nutr., 50:11-18, 2004.

MA, J.F. \& YAMAJI, N. Silicon uptake and accumulation in higher plants. Trends Plant Sci., 11:392-397, 2006.

MAUAD, M.; GRASSI FILHO, H.; CRUSCIOL, C.A.C. \& CORRÊA, J.C. Teores de silício no solo e na planta de arroz de terras altas com diferentes doses de adubação silicatada e nitrogenada. R. Bras. C. Solo, 27:867-873, 2003.

MAUAD, M. Desenvolvimento e marcha de absorção de silício em plantas de arroz sob condição de déficit hídrico e adubação silicatada. Botucatu, Universidade Estadual Paulista, 2006. 107p. (Tese de Doutorado)

MISTRO, J.C.; CAMARGO, C.E.O. \& PETTINELLI-JUNIOR, A. Avaliação de genótipos de trigo, de diferentes origens, em relação à toxicidade de alumínio. Bragantia, 60:1-9, 2001.

PIÑEROS, M.A.; JURANDIR V.; MAGALHAES, J.V.; ALVES, V.M.C. \& KOCHIAN, L.V. The physiology and biophysics of an aluminum tolerance mechanism based on root citrate exudation in maize. Plant Physiol., 129:1194-1206, 2002.
NOVAIS, R.F.; NEVES, J.C.L. \& BARROS, N.F. Ensaio em ambiente controlado. In: OLIVEIRA, A. J.; GARRIDO, W.E.; ARAÚJO, J.D. \& LOURENÇO, S., eds. Métodos de pesquisa em fertilidade do solo. Brasília, Embrapa, 1991. p.189-253. (Documentos, 3)

RAHMAN, M.T.; KAWAMURA, K.; KOYAMA, H. \& HARA, T. Varietal differences in the growth of rice plants in response to aluminum and silicon. Soil Sci. Plant Nutr., 44:423-431, 1998.

SCHLINDWEIN, J.A.; NOLLA, A.; ANGHINONI, I. \& MEURER, E.J. Redução da toxidez de alumínio em raízes de soja por culturas antecessoras no sistema plantio direto. R. Bras. Agroci., 9:85-88, 2003.

SILVA, L.M. Crescimento radicular e absorção de nutrientes de cultivares de arroz submetidos ao alumínio em solução nutritiva. Botucatu, Universidade Estadual Paulista, 2007.103p. (Tese de Doutorado)

TERRES, A.L.S.; FAGUNDES, P.R.R.; MACHADO, M.O.; MAGALHÃES JR., A.M. \& NUNE, D.D.M. Melhoramento genético e cultivares de arroz irrigado. In: GOMES, A.S. \& MAGALHÃES JUNIOR, A.M., eds. Arroz irrigado no sul do Brasil. Brasília, Embrapa Informação Tecnológica, 2004. p.161-226.

YOSHIDA, S. Fundamentals of rice crop science. Los Baños, IRRI, 1981. 269p.

WANG, J.; RAMAN, H.; ZHANG, G.; MENDHAM, N. \& ZHOU, M. Aluminum tolerance in barley (Hordeum vulgare L.): physiological mechanisms, genetics and screening methods. J. Zhejiang Univ. Sci., 7:769-787, 2006. 
